\title{
A convergência estratégica em Arranjos Produtivos Locais: uma análise sobre a cooperação entre atores em rede em duas regióes cafeeiras ${ }^{1}$
}

\author{
Paulo Henrique Montagnana Vicente Leme ${ }^{2}$, Bruno Henrique Aguiar ${ }^{3}$ e \\ Daniel Carvalho de Rezende 4
}

\begin{abstract}
Resumo: O desenvolvimento de novos Arranjos Produtivos Locais (APLs) no Brasil é um tema de extrema importância no atual contexto econômico e social brasileiro. As Indicações Geográficas (IG) surgem com o objetivo de proteger e valorizar produtos e serviços típicos de uma região. O resultado é que estes APLs que buscam reconhecimento de origem necessitam desenvolver aspectos ligados à governança local e à coordenação de relacionamentos e interesses diversos. O objetivo deste trabalho foi estudar um APL consolidado na produção de café, o do Cerrado Mineiro, em busca de aspectos estratégicos que expliquem seu sucesso e, através de uma pesquisa-ação, reproduzir as categorias estratégicas encontradas na articulação estratégica da construção da IG da região Oeste da Bahia. Nos resultados, confirma-se a validação do modelo teórico de convergência estratégica para APLs, que é definido como uma série de ações e práticas dos atores sociais inter-relacionados através de uma rede em um arranjo produtivo local, que possuem interesses e objetivos em comum definidos nas dimensões (1) organizacionais (estruturais), (2) históricas e de (3) ações coletivas em prol de um produto ou serviço. O processo de convergência não é estático, é performático, modifica as estruturas de governança e coordenação. Compreender a dinâmica destes fenômenos através de diferentes práticas estratégicas seria valioso para estudos futuros, tanto no café como em outras IGs.
\end{abstract}

Palavras-chaves: arranjo produtivo local, convergência estratégica, origem, café, governança.

Abstract: The development of new local clusters in Brazil is a very important subject in both Brazilian economic and social current scenarios. Geographical Indications (GI) arise with the objective of protecting and valuing typical products and services. These clusters that seek origin recognition need to develop aspects related to local governance and the coordination of diverse relationships and

1. Data de submissão: 24 de julho de 2017. Data de aceite: 22 de abril de 2018.

2. Universidade Federal de Lavras. Lavras-MG, Brasil. E-mail: paulo.leme@ufla.br

3. Universidade Federal de Lavras. Lavras-MG, Brasil. E-mail: brunobaratiaguiar@gmail.com

4. Universidade Federal de Lavras. Lavras-MG, Brasil. E-mail: danielderezende@ufla.br 
interests. The objective of this paper was to study a consolidated cluster in coffee production, the "Cerrado Mineiro" in search of strategic aspects that explain its success, and, through an action research, to reproduce the strategic categories found in the "Cerrado Mineiro" in the strategic articulation of the construction of the GI of "região Oeste da Bahia". The results confirm the validation of the theoretical model of strategic convergence for clusters, which is defined as a series of actions and practices of interrelated social actors through a network in a cluster, which have common interests and objectives defined in the (1) organizational (structural), (2) historical and (3) actions to develop and promote a product or service. The process of convergence is not static, it is performative, it modifies the structures of governance and coordination. Understanding the dynamics of these phenomena through different strategic practices would be valuable for future studies, both in coffee and in other GIs.

Key-words: local clusters, strategic convergence, origin, coffee, governance.

Classificação JEL: M1 Business Administration.

DOI: http://dx.doi.org/10.1590/1234-56781806-94790570109

\section{Introdução}

O desenvolvimento e o incentivo ao surgimento de novos arranjos produtivos locais no Brasil - especialmente aqueles ligados ao agronegócio - são temas de extrema importância no contexto econômico e social brasileiro. O mercado consumidor global começa a (re)valorizar a origem e procedência dos alimentos, em um movimento de crescente interesse de aproximação com os produtores (GIOVANNUCCI; BARHAM; PIROG, 2010).

As certificações de origem, ou as demarcações de origem do tipo Indicações Geográficas (IG) ${ }^{5}$, têm crescido no Brasil inseridas neste contexto. De forma obrigatória pela lei brasileira, os detentores das IGs devem representar a coletividade dos produtores daquele local específico (MAFRA, 2008; INPI, 2013; BRASIL, 2018).

O resultado indireto da busca pelas indicações geográficas é que estes agrupamentos de produtores necessitam desenvolver aspectos ligados à governança local, à definição de padrões de qualidade do produto, à comercialização e mesmo ao marketing. É uma tarefa que requer coordenação de relacionamentos e interesses diversos (GUIMARÃES FILHO, 2013).

Outra instância importante para a ação coletiva dos produtores rurais é o associativismo via Associações de Interesse Privado. Estas vêm ganhando uma importância cada vez maior nas articulações dos interesses

5. O Ministério da Agricultura define que a IG é um registro que cria uma identidade única ao produto, ligada ao processo produtivo daquele local (know-how) (BRASIL, 2018). dos produtores rurais. Talvez, sua estrutura mais flexível e o foco em objetivos comuns, que não apenas os financeiros, sejam os principais motivos para o crescimento desta modalidade. Por outro lado, a desregulamentação dos sistemas agroindustriais que ocorreu principalmente no final do século XX forçou os produtores a literalmente assumir as rédeas de seus negócios (BARRA; OLIVEIRA; MACHADO, 2007).

No caso da história do sistema agroindustrial do café no Brasil, devido à sua tradição ligada ao surgimento de muitas cooperativas, o fenômeno do associativismo via estruturas de associações é algo que vem se consolidando nos últimos 20 anos. Uma das explicações para o surgimento de novas associações é que os cafeicultores necessitaram de outras estruturas coletivas para poder representar seus interesses (BARRA; OLIVEIRA; MACHADO, 2007). Outra razão foi a desregulamentação do mercado brasileiro de café, marcada historicamente pela extinção do antigo Instituto Brasileiro do Café (IBC) (SAES, 1998) e a evolução do mercado de cafés especiais no Brasil e no mundo (GUIMARÃES et al., 2018).

Mudanças estruturais ocorridas nas cafeiculturas brasileira e mundial também foram importantes. Uma das principais motivações para esta mudança de perfil foi o fortalecimento do mercado de cafés ditos como "especiais", diferenciados pela origem ou gourmet, ou seja, que possuem características diferenciadas em relação ao café commodity produzido no País até então (LEME, 2012; GUIMARÃES et al., 2018).

Estes cafés necessitam de cuidados especiais no preparo, armazenamento e comercialização, e nota- 
damente, podem estar relacionados ao perfil dos produtores de determinada região, como no caso das Indicações Geográficas (BRASIL, 2018). Sua produção e posterior avaliação de qualidade podem demonstrar, ainda, que estas características organolépticas podem estar ligadas às características físicas da região, como solo e altitude. O crescente interesse dos mercados consumidores por cafés especiais e a própria oferta destes cafés por alguns produtores de tradicionais regiões fizeram surgir a necessidade de maior integração entre estes atores. Afinal, não basta fazer qualidade, é preciso vender qualidade.

Casos de sucesso no Brasil, como o da região do Cerrado Mineiro (SAES; JAYO; SILVEIRA, 1997; MAFRA, 2008; ORTEGA, 2008; ORTEGA; JESUS, 2011, 2012; VALENTE et al., 2013; DE LIMA FANTE; DALLABRIDA, 2016), chamam a atenção pela forma com que estes arranjos produtivos se organizaram em função de algum objetivo estratégico. No início dos anos 2010, a região do café do oeste da Bahia também iniciou ações em prol da valorização de sua origem de café. Em ambos os casos, o fato de existir uma forte convergência das ações estratégicas nestes arranjos produtivos fez com que resultados relevantes fossem alcançados, como será demonstrado neste trabalho.

A organização estratégica destes arranjos produtivos locais e suas implicações econômicas para o desenvolvimento local vêm sendo estudadas no Brasil por sua relevância no contexto acadêmico, como demonstram Caldas, Cerqueira e Perin (2005), Mafra (2008), Vieira e Pellin (2014), Dos anjos, Criado e Caldas (2013), Valente et al. (2013) e como questiona Niederle (2009) (ao analisar o caso do Vale dos Vinhedos), dentre outros inúmeros exemplos internacionais relacionados aos estudos de origem de produtos e desenvolvimento regional.

Após análise do caso de sucesso do arranjo produtivo local do café do Cerrado Mineiro, este artigo propõe o conceito de "convergência estratégica" para arranjos produtivos e o desenvolvimento local. Defende-se neste artigo que a convergência estratégica pode ser definida como uma série de ações e práticas dos atores sociais inter-relacionados através de uma rede em um arranjo produtivo local, que possuem interesses e objetivos em comum definidos nas dimensões organizacionais (estruturais), históricas e de ações coletivas em prol de um produto ou serviço.

O problema de pesquisa apresenta-se, então, em compreender os caminhos estratégicos e ações que levaram ao caso de sucesso da IG do Cerrado Mineiro: seria possível analisá-lo através de categorias de análise em comum? E mais, seria possível utilizar estas dimensões como base para iniciar um processo de obtenção do registro de uma nova IG ligada ao café, como no caso do oeste da Bahia? Este modelo teórico de análise poderia ser identificado através das características definidas no conceito de "convergência estratégica"?

O objetivo deste trabalho é, então, construir e avaliar o conceito teórico de "convergência estratégica" para arranjos produtivos locais, identificando suas dimensões através dos caminhos estratégicos e ações identificadas na análise histórica de cada APL estudado.

Para tal, duas pesquisas foram realizadas buscando confirmar e aplicar os conceitos propostos à luz das teorias de alianças estratégicas e cooperação (BEGNIS; PEDROZO; ESTIVALETE, 2005), arranjos produtivos locais (AMATO NETO, 2000, 2009) e capital relacional (VALE; AMÂNCIO; LIMA, 2006). Uma pesquisa bibliográfica e historiográfica foi conduzida no caso da região do Cerrado Mineiro e uma pesquisa-ação, inspirada nos resultados no Cerrado Mineiro, foi conduzida com os atores da região oeste da Bahia.

Além desta primeira parte introdutória, serão apresentados os conceitos de indicações geográficas e valorização da origem na segunda parte. Ainda na segunda parte serão apresentados os pressupostos teóricos que darão suporte ao conceito de "convergência estratégica". Na terceira parte, estão as metodologias de pesquisa empregadas neste estudo. Na parte 4, os casos serão apresentados e discutidos. Por fim, nas considerações finais, a discussão será retomada para analisar os prós e os contras da proposta de "convergência estratégica" para arranjos produtivos locais.

\section{Referencial teórico}

\subsection{As indicações geográficas e a valorização da origem}

A "descomoditização" do café brasileiro, os investimentos em qualidade e o surgimento de concursos de qualidade fizeram com que os cafés de diferentes regiões começassem a se destacar no cenário dos cafés especiais do Brasil (GUIMARÃES et al., 2018). A região cafeeira pioneira nesse aspecto foi a região do Cerrado Mineiro (SAES; JAYO; SILVEIRA, 1997; MAFRA, 2008). 
148 - A convergência estratégica em Arranjos Produtivos Locais: uma análise sobre a cooperação entre atores em rede em duas regiões cafeeiras

Uma forma importante de apresentar as qualidades de determinado café aos consumidores é associar seus atributos à origem. Uma origem que possua atributos de qualidade diferenciados pode ser facilmente identificada pelos consumidores nas gôndolas dos supermercados. Existem muitas ferramentas para promover uma origem; porém, a mais eficiente e reconhecida mundialmente é via indicações geográficas (IG). A IG é um nome, ou um termo, que se refere a um local geográfico particular (INPI, 2013). É usada para identificar produtos que têm qualidade e reputação únicas devido à sua origem geográfica. Os consumidores podem associar a origem à alta qualidade do produto, e como resultado, este pode conseguir um preço maior na gôndola do supermercado (GIOVANNUCCI; BARHAM; PIROG, 2010).

No Brasil, de acordo com Valente et al. (2013):

Denominação de origem (DO) e indicação de procedência (IP) compõem as duas modalidades de indicações geográficas (IGs) previstas no Brasil pela Lei de Propriedade Industrial (Lei n. 9279, de 14 de maio de 1996) e têm sido vistas como formas de mobilização e valorização dos territórios e de agregação de valor aos produtos típicos e de qualidade diferenciada.

O primeiro registro de uma indicação geográfica no Brasil foi em 1999, para a Denominação de Origem da Região dos Vinhos Verdes, de Portugal. A primeira indicação geográfica reconhecida no Brasil ocorreu em 2002. Foi a Indicação de Procedência do Vale dos Vinhedos, para vinhos tintos, brancos e espumantes (VALENTE et al., 2012).

Durante anos, os países europeus ocuparam a liderança na identificação e proteção de suas indicações geográficas, mas, nos últimos anos, os países em desenvolvimento estão mais atentos ao uso desta ferramenta que pode alavancar o desenvolvimento regional (NIEDERLE, 2009; THAINES, 2012; VALENTE et al., 2012).

As indicações geográficas pertencem exclusivamente às associações de produtores ou cooperativas que os representam. Essa é uma das características mais importantes das IGs porque, para administrar toda a estrutura necessária para registrar e monitorar a IG, os produtores precisam unir esforços e trabalhar em conjunto por um objetivo comum. Na realidade, o processo de reconhecimento da IG funciona como um incentivo poderoso para todos investirem em qualidade, estratégias de marketing e comercialização.

\subsection{Em busca da convergência estratégica}

Na literatura, o termo "convergência estratégica", ou "convergência", tem seu uso variado, referindo-se ora como processos de consultoria para gestão dentro de empresas (convergência estratégica), ora de forma como o resultado econômico (convergência), de uma relação entre produto per capita e renda, como em Barro e Sala-i-martin (1992). Delgado, Porter e Stern (2012) utilizam a "convergência" como forma de analisar o desenvolvimento econômico de clusters nos EUA.

Porém, a proposta aqui é a de colocar o termo convergência como um caminho estratégico e, ao mesmo tempo, como um objetivo para o arranjo produtivo local, acessível para os diversos atores que compõem o arranjo. Neste caso, a convergência passa a ser um objetivo estratégico, sendo desenvolvida e trabalhada na prática. Dessa forma, seria possível estimular estas práticas para que um arranjo produtivo, com atores diversos, possa atingir níveis elevados de coordenação e resultados conjuntos. Afinal, de que adianta estabelecer uma séria de táticas e planejamentos estratégicos e de marketing se não existe, atrás de uma logomarca, uma estrutura organizada e confiável que garanta o produto de qualidade? Se não houver coesão e consenso entre produtores e membros do arranjo, as estratégias estarão fadadas ao fracasso.

Ao analisar estudos sobre redes e alianças estratégicas entre organizações e empresas, fica evidente que o enfoque ora se concentra muito na organização, em termos de suas estratégias de competição e cooperação em busca de uma vantagem competitiva, ora muito no indivíduo e em suas relações de poder e acumulação de capital social (BEGNIS; PEDROZO; ESTIVALETE, 2005).

Os motivos que levam produtores e empresas rurais a se associarem incluem a necessidade de realizar compras coletivas, reduzindo preço de aquisição de insumos; realizar vendas de forma conjunta, garantindo acesso a novos mercados e compradores exclusivos; reduzir custos com operações conjuntas de compra e venda; fazer o marketing coletivo dos produtos da região, promover a origem ou marca da associação, participar de feiras internacionais etc.; dividir o ônus com pesquisas agronômicas focadas na região e defender interesses coletivos junto ao poder público. 
De fato, o principal motivo para empresas urbanas e empresas do agronegócio buscarem o associativismo é o mesmo: cooperar para melhor competir. Por isso, muitas abordagens teóricas focam nas formas organizacionais que estas associações apresentam para buscar explicar os mecanismos que garantem a cooperação e a competição (BEGNIS; PEDROZO; ESTIVALETE, 2005).

Alguns autores contrapõem esta ótica tradicional à uma visão mais moderna, a das redes de cooperação. Na literatura tradicional, as organizações são visualizadas como entidades autônomas, inseridas em um determinado ambiente. Essa abordagem tornou-se, inclusive, base de referência para importantes trabalhos na área de estratégia empresarial, como por exemplo, os de Michael Porter (1998) e de estudos subsequentes como os de Delgado, Porter e Stern (2012). A interdependência competitiva é considerada apenas um dado da realidade e deve ser conhecida e incorporada ao posicionamento estratégico da empresa (VALE; AMÂNCIO; LIMA, 2006).

Vemos, portanto, que no agronegócio, talvez como em nenhum outro sistema industrial, a cooperação entre empresas (ou entre produtores) é um fator fundamental para que em conjunto, estes consigam ser competitivos. Desta forma, antes de serem competidores por clientes e mercados, estes produtores são parceiros, que cooperam em busca de um objetivo comum. O termo utilizado por diversos autores para se referir a este fenômeno é "coopetição" (BRANDENBURGER; NALEBUFF, 1997; BEGNIS; PEDROZO; ESTIVALETE, 2005).

De fato, a busca pela competitividade transformou-se no grande objetivo das empresas e até mesmo das economias nacionais. Pode-se inferir que o próprio sentido da competitividade foi alterado, passou de algo entre empresas para algo entre territórios e nações. Regiões vencedoras no mundo vêm demonstrando a importância de fatores como especialização produtiva, aprendizado baseado na interação entre diferentes empresas e instituições, capacidade de cooperação, esforço coletivo para a inovação, qualidade da mão de obra, ambientes econômico, social e cultural favoráveis, entre outros (VALE; AMÂNCIO; LIMA, 2006).

\subsection{Arranjos produtivos locais}

Os relacionamentos entre empresas também podem ser estruturados em forma de redes. Estas redes normalmente se desenvolvem e são estruturadas em regiões específicas, formando complexos industriais e os clusters regionais ou arranjos produtivos locais (AMATO NETO, 2000, 2009; PORTER, 1998).

No agronegócio, o conceito de arranjo produtivo também pode ser usado. Por exemplo, podemos citar os arranjos produtivos vinícolas da região de Champagne na França ou do Vale dos Vinhedos no Brasil. Porém, é pertinente olhar outras formas de agrupamento no agronegócio que possuem estas características. Normalmente, estes agrupamentos surgem em novas regiões de fronteira, onde o desenvolvimento econômico é praticamente nulo. É a partir da agricultura e pecuária que se iniciam a construção de novos arranjos nestes locais. Não são apenas agrupamentos de produtores do mesmo ramo (algodão, soja, café, frutas etc.), pois podem envolver comerciantes e indústrias de insumos de um lado e, do outro lado, fornecedores de serviços de armazenagem, logística, comércio, exportação etc.

A aplicação do conceito de arranjos produtivos no agronegócio permite que possamos ampliar também nossas percepções quanto aos relacionamentos em rede que se formam nestes locais. Por exemplo, o surgimento de novas cidades e da própria economia regional em locais antes esquecidos. Estes novos e incipientes arranjos atraem investimentos governamentais. É o desenvolvimento regional em sua forma mais pura, partindo da produção de bens primários e conduzindo o surgimento de novos arranjos. Seria plausível, portanto, incluir na busca pela "convergência estratégica" a questão do local. Podemos definir um arranjo produtivo como a concentração setorial e espacial de empresas que buscam de forma deliberada ou não ganhos de eficiência coletiva e a obtenção de vantagens competitivas (AMATO NETO, 2000).

A descrição moderna de um arranjo produtivo apenas mostra um fenômeno frequentemente observado na história, que inclui a concentração territorial das atividades econômicas. Esta concentração territorial é um fator importante para o desenvolvimento econômico, territorial e da inovação e da competitividade (GASCÓN, 2010).

Outro termo encontrado constantemente na literatura é "arranjos produtivos locais" (APL), e este termo é mais adequado para descrever o que acontece no agronegócio. Os arranjos produtivos locais são territórios, inclusive os chamados "rurais", que já apresentam elementos de aglomeração de micro e pequenos negó- 
150 - A convergência estratégica em Arranjos Produtivos Locais: uma análise sobre a cooperação entre atores em rede em duas regiões cafeeiras

cios, associados ou não entre si ou a médias e grandes empresas, que operem em forma de rede (empresas-rede), ou mesmo concentrações de grandes indústrias que apresentem elevado potencial de integração com micro e pequenos negócios.

Normalmente, nestes arranjos as empresas estão aglomeradas e apresentam algum tipo de especialização produtiva e, muito importante, elas possuem algum vínculo de articulação, interação, cooperação e aprendizagem entre si e com outros atores locais, tais como: governo, associações empresariais, instituições de crédito, ensino e pesquisa. Em qualquer arranjo deve- se sempre considerar: as redes de atores locais; as potencialidades, vocações e oportunidades; as vantagens comparativas e competitivas; os recursos naturais renováveis ou não-renováveis; a infraestrutura existente; o capital humano (conhecimentos, habilidades e competências das pessoas); o capital social (os níveis de confiança, cooperação, organização e participação social); a cultura empreendedora (níveis de autoestima, autoconfiança, capacidade de iniciativa); a cultura local (os costumes, os valores e crenças locais, as tradições); a poupança local; a capacidade de atrair investimentos, dentre outros.

Os atores sociais que constroem esta imbricada rede possuem grande importância. A presença de atores no território e a capacidade explícita ou tácita de atuarem em um mesmo setor produtivo é a chave para a construção de um desenho territorial que se traduza, efetivamente, numa unidade de desenvolvimento, pois revela o seu protagonismo local. São estes indivíduos que instituem o território como uma unidade de desenvolvimento. Ninguém melhor do que eles para reconhecer e valorizar os ativos locais, identificar potencialidades, vocações, oportunidades e vantagens comparativas e competitivas.

Baseado nos trabalhos de autores como Marteleto e Silva (2004), Amato Neto e Amato (2009), Vale, Amâncio e Lauria (2006), podemos dizer que alguns fatores são fundamentais, como: (1) o capital humano (os conhecimentos, habilidades e competências da população local, as condições e a qualidade de vida); (2) o capital social (os níveis de confiança, cooperação, reciprocidade, organização social e empoderamento da população local); (3) a governança: diferentes modos de liderança, coordenação, intervenção, participação e negociação dos conflitos nos processos decisórios locais e (4) o uso sustentável do capital natural.
Desta forma, o arranjo produtivo compreende um recorte do espaço geográfico (parte de um município, conjunto de municípios, bacias hidrográficas, vales, serras etc.) que possui sinais de identidade coletiva (sinais sociais, culturais, econômicos, políticos, ambientais, históricos etc.); mantém ou possui a capacidade de promover a convergência estratégica em termos de expectativas de desenvolvimento; estabelece parcerias e compromissos para manter e especializar os investimentos de cada um dos atores no próprio território e promove ou é passível de uma integração econômica e social no âmbito local.

Pode-se considerar que estes arranjos produtivos favorecem uma forma alternativa de organização da cadeia de valor. Comparada com as transações de mercado entre compradores e vendedores dispersos e heterogêneos, a proximidade física de empresas e instituições, assim como as sucessivas trocas entre elas, facilita a coordenação e amplia a confiança. E sem impor às empresas as características de inflexibilidade da integração vertical ou os desafios de criar e manter associações formais como redes, alianças e parcerias. Um arranjo de empresas e instituições independentes e informalmente vinculadas representa um modelo organizacional robusto, que oferece vantagens em fatores como eficiência e flexibilidade (PORTER, 1998).

Nesse sentido, os arranjos produtivos afetam a capacidade de competição de três maneiras principais: (1) aumentando a produtividade das empresas sediadas na região; (2) indicando a direção e o ritmo da inovação, que sustentam o futuro crescimento da produtividade e (3) estimulando a formação de novas empresas, o que expande e reforça o próprio arranjo produtivo.

Para a convergência estratégica, o fluxo de informações dentro do arranjo produtivo é fundamental, pois é ele que irá garantir a convergência de opiniões e pensamentos entre os atores sociais. Promover o intercâmbio de informações e a troca de experiências é chave para o sucesso das iniciativas propostas no arranjo produtivo. Além disso, os relacionamentos pessoais e os laços com a comunidade promovem a confiança e facilitam o fluxo de informações.

O grande número de ligações dos membros de um arranjo produtivo faz com que o todo seja maior do que a simples soma das partes. Em um arranjo produtivo de turismo, por exemplo, a satisfação do turista depende não apenas do apelo da atração primária do 
local, mas também da qualidade e eficiência de empresas correlatas - hotéis, restaurantes, centros comerciais e meios de transporte. Como os membros do cluster são mutuamente dependentes, o bom desempenho de um pode aumentar o sucesso dos demais. No caso das estratégias de marketing, a articulação do arranjo produtivo também é fundamental. Para seu sucesso, a convergência estratégica deve ser alcançada entre os atores interligados pela rede do arranjo.

Da teoria de redes é possível extrair alguns conceitos centrais para esclarecer a importância da convergência estratégica, como a confiança, o aprendizado e o compartilhamento de recursos entre os diversos atores envolvidos. Para isto, faz-se necessário compreender melhor o significado de "capital relacional", oriundo e relacionado com o conceito de capital social (VALE; AMÂNCIO; LIMA, 2006).

[...] quanto mais redes e conexões de interesse socioeconômico existirem em um dado território - conectando os atores produtivos entre si e estes com o restante do mundo e os centros mais dinâmicos -, maior o estoque de capital relacional aí existente e maiores suas perspectivas de crescimento e desenvolvimento. De particular importância nesse contexto é a inserção das empresas em vários tipos de redes locais (VALE; AMÂNCIO; LIMA, 2006, p. 138).

O acesso à informação é um elemento-chave para o desenvolvimento econômico e social de comunidades e grupos sociais. A capacidade de obter informações, além dos contornos restritos da própria comunidade, é parte do capital relacional dos indivíduos e grupos (MARTELETO; SILVA, 2004). Desenvolvendo e estruturando estas relações sociais em rede que se constrói o capital relacional de determinado arranjo produtivo. Porém, mais do que o capital relacional, os atores deste arranjo devem estar orientados estrategicamente para atingir suas metas e objetivos em comum. Para isso, precisam chegar à convergência estratégica.

\subsection{Apresentando o conceito de convergência estratégica}

De acordo com o referencial apresentado, a convergência estratégica pode ser definida como uma série de ações e práticas dos atores sociais inter-relacionados através de uma rede em um arranjo produtivo local, que possuem interesses e objetivos em comum definidos nas dimensões organizacionais (estruturais), históricas e de ações coletivas em prol de um produto ou serviço.

Esta definição toma como pressuposto os conceitos de capital humano, capital social, capital relacional, governança e uso sustentável do capital natural, conforme destacado por Marteleto e Silva (2004), Amato Neto e Amato (2009), Vale, Amâncio e Lauria (2006). Também leva em consideração os aspectos fundamentais de uma Indicação Geográfica, como colocados por Valente et al. (2013), que são o (1) regulamento de uso, (2) delimitação da área e (3) diferenciação do produto.

E com isso, são definidas três dimensões de análise importantes para a convergência estratégica:

- Estrutura de governança presente no APL;

- A história do APL (que representa o capital social e relacional);

- Ações coletivas em prol do produto, tal como modo de produção, o "saber fazer", aspectos culturais e tecnológicos.

Os atores presentes em um APL passível de obter o reconhecimento de IG podem partir de objetivos distintos e práticas estratégicas diferentes, mas devem convergir para o mesmo ponto, para o mesmo objetivo, que é a valorização do seu produto, de sua localidade e do capital humano envolvido.

A convergência estratégica envolve os atores sociais e reconhece que independente de quaisquer planos e estratégias, o mais importante é que os diversos elos desta rede estejam convergindo seu pensamento para o mesmo objetivo estratégico. Em verdade, é tão difícil mensurar a convergência estratégica como qualquer outro atributo subjetivo de uma rede.

Na convergência estratégica, os diversos atores da rede estabelecem suas próprias metas estratégicas, se organizam em suas comunidades, em seus pequenos arranjos, praticam a estratégia (WHITTINGTON, 2011) de forma diferenciada, partindo de pontos diferentes, mas convergindo para o mesmo objetivo. Quando todas as condições da convergência estratégica ocorrem em um cluster, "todos os caminhos levam à Roma". A Figura 1 mostra o desenho do que seriam as práticas da estratégia, convergindo para um objetivo em comum, tomando como figura emblemática cordas entrelaçadas que formam uma única corda. 
152 A convergência estratégica em Arranjos Produtivos Locais: uma análise sobre a cooperação entre atores em rede em duas regiões cafeeiras

Figura 1. Modelo para a convergência estratégica em clusters ou APLs

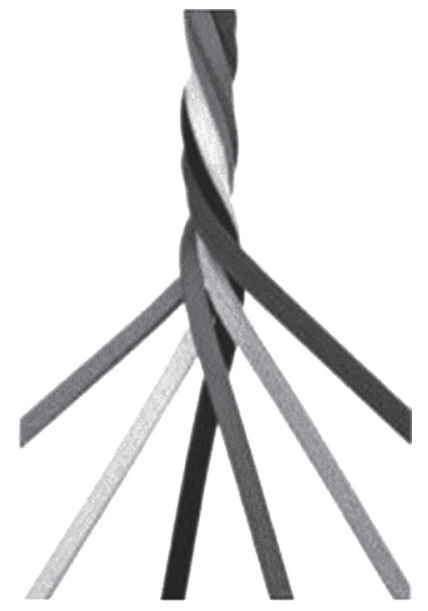

Os caminhos estratégicos seriam identificados então pelas dimensões (1) estrutura de governança presente no APL; (2) pela história do APL (que representa o capital social e relacional); e (3) pelas ações coletivas em prol do produto, tal como modo de produção, o "saber fazer", aspectos culturais e tecnológicos. As práticas estratégicas iriam mostrar a ação dos atores em determinados momentos históricos, sendo as evidências empíricas da convergência estratégica no APL.

Sendo assim, o interesse pela convergência estratégica está em analisar as práticas estratégicas, que são o ponto de partida e que constroem os diversos caminhos estratégicos possíveis. Cada ator ou grupo de atores (no caso de diversas associações ou cooperativas) irá construir seu caminho estratégico.

Se houver convergência estratégica nas dimensões de análise identificadas, espera-se que o cluster atinja a maturidade e esteja claro - no discurso e na prática dos atores - que existe um objetivo em comum. A convergência estratégica se manifesta de maneiras diversas, a depender do arranjo produtivo, da cultura local, do desempenho dos atores da rede.

\section{Metodologia}

Verificar a existência da convergência estratégica requer um trabalho de observação da história dos atores e da formação daquele arranjo produtivo. Também requer compreender quais os fatos e ações que ajudaram a construir as estratégias que levaram o APL ao sucesso. Neste estudo, a decisão foi por realizar duas pesquisas em dois estudos de caso diferentes. Trata-se de um estudo empírico e descritivo, caracterizado como qualitativo, uma vez que permite analisar objetos subjetivos como percepções, compreensão do contexto organizacional e dinâmica das interações grupais (GODOY, 2006).

No primeiro estudo, escolheu-se um exemplo de sucesso no agronegócio café, mais especificamente o estudo de caso do café da região do Cerrado Mineiro. Para verificar a presença de elementos que comprovem a existência da convergência estratégica, partiu-se para uma pesquisa documental (GODOY, 2006) de inspiração historiográfica (PIERANTI, 2008), analisando documentos, artigos, teses, notícias e entrevistas de atores que praticaram as estratégias que levaram ao sucesso das ações neste arranjo específico.

O objetivo desta análise documental, e que se baseia também em conversas com os atores da região e no conhecimento do pesquisador sobre o Cerrado Mineiro, é o de encontrar momentos importantes, buscando fatos que ocorreram e que tenham marcado de alguma forma a região. Por exemplo, datas importantes de fundação de estruturas de governança local, marcos na construção da histórica da região segundo os 
próprios atores, dispositivos e ferramentas estratégicas que ajudaram a coordenar ações, propostas de marketing e estratégia conceituais, ações desenvolvidas ao longo do tempo que envolveram o café e os produtores da região, ações de entidades apoiadoras do processo de construção, e o desenvolvimento do processo de construção e compilação da documentação necessária para solicitar o registro da Indicação de Procedência.

Os dados serão apresentados de forma agrupada, nas dimensões: (1) estrutura de governança; (2) aspectos importantes e relevantes da história do APL e (3) ações coletivas em prol do produto.

Numa segunda etapa, escolheu-se um caso "em construção" de um processo de indicação geográfica, o caso do café da região oeste da Bahia, onde um dos pesquisadores atuou na orientação do processo de construção da história e dos documentos principais para a obtenção do reconhecimento por parte do Instituto Nacional de Propriedade Industrial (INPI). Para este fim, foi conduzida uma pesquisa-ação que, segundo Macke (2006), preocupa-se com a elaboração de diagnósticos, a identificação de problemas e a solução dos mesmos por meio da pesquisa.

Neste caso, o pesquisador e os atores envolvidos no processo utilizaram os exemplos de convergência estratégica do Cerrado Mineiro para construir ações que pudessem replicar o efeito observado no outro caso. Com isso, o sistema de pesquisa-ação, proposto por Macke (2006) foi replicado diversas vezes, a cada visita e reunião com os atores. Isto foi necessário para possibilitar que as práticas que pudessem levar à convergência estratégica emergissem de diversos pontos. Aqui também o eixo central foi o processo de construção da documentação para a obtenção da indicação de procedência. Para coleta dos dados utilizou-se uma caderneta de campo, entrevistas com os principais atores e análise documental. As dimensões principais e os fatos e ações importantes serão apresentados a seguir.

\section{Análise dos resultados}

\subsection{Análise da convergência estratégica na história do Cerrado Mineiro}

O Cerrado Mineiro engloba hoje 55 municípios localizados no noroeste do estado de Minas Gerais. São aproximadamente 4.500 produtores de café que produ- zem cerca de 5 milhões de sacas de $60 \mathrm{~kg}$ de café em 170.000 ha. A região também foi a primeira a obter seu registro de Indicação de Procedência para o produto café junto ao Inpi, em 2005.

A história da cafeicultura e dos próprios cafeicultores na região já traz um dos aspectos mais importantes e que conferem uma característica essencial em sua trajetória: o pioneirismo. Os cafeicultores pioneiros na produção de café comercial na região vieram do Paraná e São Paulo na década de 1970, após forte geada nestes estados (MAFRA, 2008). O espírito empreendedor é algo que faz parte da cultura desta região, ajudou os produtores a quebrarem uma série de barreiras, como por exemplo, a do marketing da região como forma de valorização do café (SAES et al., 1998). Segundo relatos de representantes da região, um dos maiores objetivos era eliminar o "diferencial de preço" do café produzido no Cerrado Mineiro em relação ao café produzido no sul de Minas Gerais.

Em 1991, a torrefadora italiana Illycaffè iniciou seus concursos de qualidade no Brasil buscando incentivar a produção de cafés naturais de qualidade. O perfil de xícara, ou de qualidade dos cafés do Cerrado Mineiro durante a época de realização destes primeiros concursos se encaixava perfeitamente na qualidade desejada pela empresa italiana. Isto se refletiu na premiação e boa colocação dos cafés do Cerrado Mineiro neste concurso nos primeiros anos de certame (SAES et al., 1998). E este foi outro ponto que ajudou os produtores de café da região a primeiro perceberem que sua dedicação resultava em valorização de seu produto e, em segundo lugar, a perceber que os diferenciais de preço em relação ao café do Sul de Minas não representavam a realidade em termos de qualidade. Segundo um dos representantes da região, no dia em que o preço do café do Cerrado entrou na pauta do programa "Globo Rural" de domingo como uma região produtora, os produtores perceberam que seus esforços haviam sido recompensados.

A governança é outro ponto de destaque na história da região do Cerrado Mineiro (SAES et al., 1998; ORTEGA, 2009). Como descrito por Mafra (2008), a história do Cerrado Mineiro tem como ponto importante a criação do Conselho das Associações de Cafeicultores do Cerrado (Caccer) em 1992, que já nasceu com o objetivo de valorizar o café da região e congregava associações e cooperativas dos municípios do cerrado. Uma de suas fundadoras era a Associação 
154 - A convergência estratégica em Arranjos Produtivos Locais: uma análise sobre a cooperação entre atores em rede em duas regiões cafeeiras

dos Cafeicultores de Patrocínio (Acarpa) que protagonizou um evento importante para a construção da coletividade da região. Após a extinção do Instituto Brasileiro do Café (IBC), o prédio que seria destinado ao Ministério da Agricultura foi ocupado pelos produtores de Patrocínio, que negociaram o repasse do prédio e das instalações aos agricultores (MAFRA, 2008). Este movimento foi coordenado por um importante líder da região, que ajudou a congregar e dar direção às ações do Caccer nos anos subsequentes.

O Caccer ajudou a projetar a imagem da região no exterior, registrou a marca "Café do Cerrado" em 1993, lutou pela criação de estruturas de apoio como a Cooperativa dos Cafeicultores do Cerrado Ltda. (Expocaccer), da Fundação de Desenvolvimento do Café do Cerrado (Fundaccer) que tiveram importante papel na execução de estratégias de exportação e coordenação no Cerrado Mineiro. Por fim, em 2011, o Caccer mudou sua denominação para Federação dos Cafeicultores do Cerrado Mineiro.

A busca da indicação geográfica do Cerrado Mineiro foi outro marco para a região. Atualmente, a indicação de procedência (IP) da região do Cerrado Mineiro é coordenada pela Federação dos Cafeicultores do Cerrado. O antigo Caccer foi a primeira instituição no Brasil a depositar um pedido de registro de Indicação de Procedência em 1995, após dez anos de idas e vindas, finalmente em 2005 a região foi reconhecida pelo Inpi. Para os representantes da região, a busca pela IP do Cerrado Mineiro foi um motivo de agregar esforços em prol de um interesse em comum. As diversas ações empreendidas para este fim, como a criação de um sistema de certificação próprio, o levantamento histórico, a definição de padrões de qualidade, o desenvolvimento de concursos de qualidade, seminários e congressos para disseminar informações e unir os produtores etc., atuaram, de forma dispersa, mas precisa, em prol da convergência estratégica do arranjo produtivo.

A questão da qualidade, em seus diversos aspectos estava presente, desde a qualidade do produto café, quanto à qualidade do processo produtivo e mesmo a comunicação através de um sinal de qualidade (selo da IP), como analisa Leme (2012).

Por fim, em 2012 a Federação lançou uma nova estratégia de comunicação visual e de propaganda utilizando a essência de sua história, criando o conceito de "café de atitude", como forma de ligar a história da região ao orgulho e sentimento de pertencimento dos cafeicultores do Cerrado Mineiro.

A convergência estratégica é algo que pode ocorrer de diversas formas. Tudo irá depender da coesão do sistema, das relações entre os atores e da forma de comunicação (intensidade e direção) entre eles. No caso do Cerrado Mineiro, como citado, a questão do pioneirismo/empreendedorismo é fundamental. O fato de o perfil tecnológico e profissional dos produtores ser elevado faz com que as mentes se abram e busquem saídas diferentes para lidar com os problemas em comum. Podemos dizer que este espírito - pioneiro e desbravador - contagiou os produtores, desenvolvendo um capital humano muito diferenciado de outras regiões cafeeiras. Novos conhecimentos, habilidades para lidar com a governança do arranjo produtivo e a competência profissional para produzir cafés de qualidade e competitivos foram razões que ajudaram os produtores a conquistar vitórias estratégicas importantes.

Do lado do capital social e relacional (VALE, 2006; VALENTE et al., 2013), percebe-se que a criação de estruturas de governança de diversos tipos acompanhou a evolução da região. A própria Federação dos Cafeicultores do Cerrado é composta por nove cooperativas, sete associações e uma fundação. Na história do APL, a emblemática tomada do ex-prédio do IBC pelos cafeicultores de Patrocínio mostra a força das relações, que de certa forma perduram, e são incentivadas até hoje. Em recente campanha de marketing do Cerrado Mineiro, vemos que o orgulho dos pioneiros e de seus descendentes é hoje uma bandeira da região. A coesão é fluída, e claro, como em muitos arranjos produtivos as diferenças existem, mas todos sabem onde querem chegar: na valorização de seu produto, de sua região e de sua história. Esta é a convergência estratégica do Cerrado Mineiro.

Cabe destacar que, apesar do comportamento carona (free-rider) (AZEVEDO, 2001), pode-se inferir que um comportamento em prol do interesse comum, que levou a práticas estratégicas que favoreciam a coletividade, prevaleceu diante dos objetivos individuais.

Como evidência, cita-se a presença de estruturas de governança como a Federação, a Expocaccer, a Fundaccer e, ainda, uma representante dos pequenos produtores da região, a Associação de Pequenos Produtores do Cerrado (Appcer) demonstra o alto nível de governança coletiva da região. Além destas estruturas associativas, vemos a presença de certifica- 
doras como a UTZ Certified, Rainforest Alliance (RAS), o sistema de Comércio Justo e Solidário (Fairtrade), as certificações de empresas privadas como a Nucoffee e a Nespresso AAA etc. (LEME, 2012).

Por fim, podemos avaliar que a gestão de qualidade da produção do café do Cerrado ajuda na sustentabilidade econômica, ambiental e social. Existem produtores com custos de produção extremamente competitivos mesmo em situações de crise (BLISKA et al., 2009). O número de produtores certificados no Cerrado Mineiro pelas principais certificações como a UTZ Certified e a RAS é o maior do Brasil. E a forte presença dos produtores do Cerrado Mineiro em concursos de qualidade do Brasil, e tendo a qualidade reconhecida por compradores internacionais, demonstra que a gestão da qualidade é um fator essencial para o sucesso da região, sendo evidência da dimensão em prol do produto, característica importante para a confirmação da convergência estratégica.

O resgate histórico da região e as diversas evidências da convergência estratégica neste arranjo produtivo demonstram alguns dos motivos pelos quais o Cerrado Mineiro é hoje a maior referência em marketing e organização no agronegócio café brasileiro.

As ações estratégicas que foram desenhadas, ou que emergiram da prática dos atores desta região convergiram para um único objetivo, a valorização de seu território. A busca pela Indicação de Procedência do Cerrado Mineiro foi um fator-chave, mas não o único que ajudou na criação da convergência estratégica.

Seria possível replicar as ações estratégicas de convergência adotadas pelo Cerrado Mineiro? Provavelmente sim, mas com adaptações para o contexto local. É o que veremos no caso do oeste da Bahia.

\subsection{Em busca da convergência estratégica no oeste da Bahia}

Neste estudo de caso, a pesquisa foi conduzida nos moldes da pesquisa-ação (MACKE, 2010). Primeiramente elaborou-se uma análise para compreender o contexto da região (MACKE, 2010). Os planos de intervenção acompanharam a necessidade das etapas de processo e podem ser divididos em: (1) resgate histórico; (2) estrutura de governança; (3) regulamento de uso e (4) construção da marca. Neste caso, o "regulamento de uso" e a marca se referem à dimensão específica do modelo de convergência estratégica.
Neste artigo, deixaremos em suspensão a rica história do oeste da Bahia para analisar os processos que foram conduzidos de forma a conseguir construir a convergência estratégica para este arranjo produtivo. Porém, alguns aspectos relevantes deste histórico serão destacados.

A história da cafeicultura no oeste da Bahia possui forte ligação com a história do Cerrado Mineiro. Dentre os pioneiros da produção de café na região estão muito mineiros do Cerrado que migraram para a região ou que adquiriram propriedade para expandir seus cultivos.

A região oeste da Bahia localiza-se à margem esquerda do rio São Francisco, com superfície equivalente a 162 mil km² e população aproximada de 850 mil habitantes, englobando 39 municípios, ocupando $28,5 \%$ do território do estado da Bahia. O relevo é formado por chapadas, encostas e planuras ou vales, seus solos são profundos, diversificados, com boa constituição física e facilmente mecanizáveis (AIBA, 2006).

Durante o processo de construção do levantamento histórico do oeste da Bahia e da cafeicultura e cafeicultores (principalmente) da região, muito além de buscar dados e documentos, o objetivo era buscar algo em comum, que representasse um símbolo para os pioneiros da região. Aqui, assim como no Cerrado Mineiro, a imagem do empreendedor/pioneiro prevalece como importante para a convergência estratégica.

Este ponto foi encontrado na história do primeiro cafeicultor a realizar a produção comercial de café com irrigação na região, o Sr. João Barata. Nas entrevistas, líderes e cafeicultores da região demonstraram fortemente sua admiração pelo português que, com 70 anos de idade migrou para o oeste da Bahia para plantar café irrigado em 1994. Este ponto foi essencial para o início da construção da identidade da região. O envolvimento dos diversos atores nesta etapa foi essencial para o sucesso do projeto.

A produção de café no oeste da Bahia é muito parecida com a do Cerrado Mineiro. Porém, no oeste da Bahia o perfil dos produtores é de cafeicultores médios e grandes, com alta escala e um dos menores custos de produção do Brasil (BLISKA et al., 2009). A qualidade de bebida do café é homogênea, e dadas as condições climáticas da região, a produção de café do tipo "natural" se destaca. Esta consistência de qualidade (grandes volumes com qualidade homogênea) chama a atenção de compradores internacionais e alavancou o reconhe- 
156 - A convergência estratégica em Arranjos Produtivos Locais: uma análise sobre a cooperação entre atores em rede em duas regiões cafeeiras

cimento da região para a solicitação de um pedido de Indicação de Procedência junto ao Inpi.

Um evento importante foi buscar a convergência estratégica através da definição do perfil de qualidade do café da região. A Abacafé (representante dos cafeicultores da região) organizou um workshop em 2012 com os principais provadores de café da região para traçar o perfil de qualidade do produto. Muito mais do que um resultado empírico, o acompanhamento da reunião permitiu ao pesquisador perceber a construção de um capital simbólico. Os provadores de café, de empresas e cooperativas da região discutiram e concordaram que existia uma evolução da qualidade da bebida do café em curso. E mais, puderam discutir sobre suas avaliações e traçar um perfil do café. Isto ajudou todos a definir seus padrões para estratégias de comercialização futuras.

A definição de um padrão de qualidade para o produto que irá receber a futura Indicação de Procedência foi muito mais do que um evento meramente técnico, foi a possibilidade de comunicar valores e estreitar relações.

Como visto no exemplo do Cerrado Mineiro, a governança e as lideranças locais foram chave na construção da convergência estratégica. A Abacafé desempenhou este papel no oeste da Bahia; porém, a liderança no início da história do café na região foi da Associação dos Agricultores e Irrigantes da Bahia (Aiba). A Aiba ajudou a incentivar o cultivo na região e desenvolver as bases tecnológicas de uma cafeicultura altamente tecnificada e completamente diferente de outras regiões brasileiras. Relatos de pesquisadores, consultores e produtores demonstraram a importância de possuir um problema em comum: a falta de orientações técnicas para a cultura do café na região.

Tanto a Aiba como a Abacafé trabalharam e trabalham (em parceria com instituições de pesquisa) de forma conjunta para construir um pacote tecnológico para a cafeicultura da região, ponto que será essencial para o futuro do oeste da Bahia. Esta é outra evidência de convergência estratégica. Neste ponto da governança, a intervenção deu-se na busca por valorizar as jovens lideranças da Abacafé neste contexto histórico. O espírito de renovação dos presidentes da Abacafé durante e depois do processo de construção do documento da IP foi fundamental. Aqui, mais uma vez, são as pessoas, o capital humano, que constroem a convergência. Além disto, a presença de diretores executivos na Abacafé e na Aiba - prática estratégica semelhante à adotada no Cerrado Mineiro - foi importante como canal de comunicação, de cobrança e convencimento dos cafeicultores em prol da busca pela valorização da origem. Uma associação representativa (não é uma cooperativa), atuante e com gestão executiva profissional é um ponto de convergência estratégica.

\section{Considerações finais}

A convergência estratégica é um processo dinâmico, não há dúvida que mudanças na governança e perda de foco podem levar ao fracasso desta busca, mas nos dois arranjos produtivos estudados existe um sentimento de "saber onde queremos chegar". Podemos inferir, assim, que a convergência estratégica não é um processo estático, é mutante, é performática, são os atores que a constroem, e ao mesmo tempo, ela modifica as estruturas de governança e coordenação do arranjo produtivo.

Os resultados deste estudo apontam, enfim, para três importantes dimensões que devem servir de análise e exemplo para estudos de relacionados à valorização da origem de produtos e serviços ligados a indicações geográficas, que podem ser resumidos na Figura 2.

Na Figura 2 estão delineadas as dimensões ligadas à (1) estrutura organizacional do APL; a (2) história das pessoas e da região e a (3) dimensão do produto. Os caminhos estratégicos, revelados através da reconstrução histórica, demonstram que através de diversas práticas estratégicas, agrupadas nestas dimensões, os atores do Cerrado Mineiro e do oeste da Bahia conseguiram atingir a convergência estratégica.

Os exemplos do Cerrado Mineiro e mesmo exemplos pontuais de outras regiões cafeeiras foram importantes para construir a convergência estratégica no oeste da Bahia. Vale ressaltar que este processo ainda está em construção na percepção dos pesquisadores e mesmo dos atores. As cordas estratégicas (caminhos) ainda estão em processo de entrelaçamento. Ou seja, se os caminhos estratégicos discutidos neste estudo de caso específico foram mesmo importantes para a convergência estratégica, só uma análise futura poderá confirmar.

A emergência de práticas estratégicas ocorre a todo o momento. Nos resultados da pesquisa-ação no oeste da Bahia é possível perceber que elas foram 
Figura 2. Modelo para a convergência estratégica em clusters ou APLs

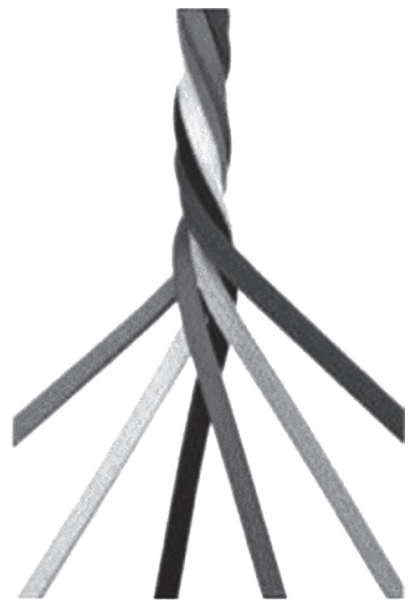

Convergência estratégica

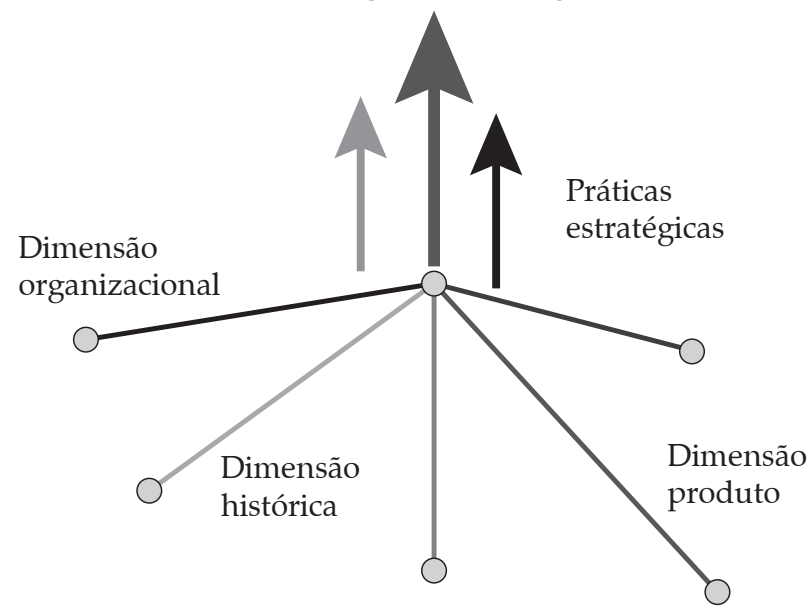

Caminhos estratégicos

Fonte: Elaborado pelos autores.

se alinhando ao objetivo maior de valorizar o café e os produtores da região. $\mathrm{O}$ processo de construção e coleta dos documentos da IP, o levantamento histórico, a estrutura de governança, o regulamento de uso e a construção da marca, foram ferramentas estratégicas utilizadas em função da construção da convergência estratégica.

O que se pode confirmar é que o modelo proposto de convergência estratégica que busca analisar as práticas e os caminhos estratégicos que vão se entrelaçando ao longo do tempo (e da história da região) é plausível. Ou seja, com ele é possível que pesquisadores analisem se existe a convergência estratégica em um APL. É claro, o modelo é uma ferramenta, e cada prática e caminho serão diferentes em cada contexto. Por isso, a pesquisa do tipo pesquisa-ação é tão interessante.

As limitações deste estudo estão na particularidade destes estudos de caso. Seria interessante aplicar os conceitos de convergência estratégica e suas dimensões em outros clusters fora do agronegócio café ou mesmo fora do agronegócio, aproveitando o grande surgimento de IGs no Brasil. Também seria válido estudar se a convergência estratégica, nos moldes propostos neste artigo, aconteceu em outros arranjos produtivos. Novas metodologias quantitativas e qualitativas poderiam ser utilizadas para tal.

Por fim, acreditamos na riqueza deste referencial e na importância prática, para pesquisadores e principal- mente gestores, da convergência estratégica em arranjos produtivos. Compreender melhor estes fenômenos em sua essência, em sua ocorrência, seria valioso para estudos futuros.

\section{Referências}

AIBA. VI Anuário de pesquisa da cafeicultura irrigada do Oeste da Bahia. Barreiras-BA, 2006.

AMATO NETO, J. Redes de cooperação produtiva e clusters regionais: oportunidades para as pequenas e médias empresas. São Paulo: Atlas, Fundação Vanzolini, 2000.

; AMATO, R.C.F. Capital social: contribuições e perspectivas teórico-metodológicas para a análise de redes de cooperação produtiva e aglomerações de empresas. Revista Gestão Industrial, v. 5, n. 1, 2009.

AZEVEDO, P. F. Informação e barganha: implicações estratégicas em arranjos verticais. In: SEMINÁRIO BRASILEIRO DA NOVA ECONOMIA INSTITUCIONAL, 2, 2001, Campinas. Anais... Campinas: Instituto de Economia Unicamp, 2001.

BARRA, G.M.J.; OLIVEIRA, V.C.S.; MACHADO, R.T.M. $O$ papel das associações de interesse privado no mercado cafeeiro brasileiro. Revista de Gestão USP, v. 14, n. 2, p. 17-31, 2007.

BARRO, R.J.; SALA-I-MARTIN, X. Convergence. Journal of political Economy, p. 223-251, 1992. 
158 - A convergência estratégica em Arranjos Produtivos Locais: uma análise sobre a cooperação entre atores em rede em duas regiões cafeeiras

BEGNIS, H.S.M.; PEDROZO, E.A.; ESTIVALETE, V.F.B. Cooperação enquanto estratégia segundo diferentes perspectivas teóricas. In: Encontro Nacional da Associação Nacional dos Programas de Pós-Graduação em Administração. Anais..., 2005. Rio de Janeiro: Enanpad.

BLISKA, F.M.M. et al. Custos de produção de café nas principais regiões produtoras do Brasil. Informações Econômicas, São Paulo, v. 29, n. 8, p. 5-20, 2009.

BRANDENBURGER, A.M.; NALEBUFF, B.J. Co-Opetition: A Revolution Mindset That Combines Competition And Cooperation: The Game Theory Strategy That's Changing. Currency Doubleday, 1997.

BRASIL. O que é Indicação Geográfica (IG)? Disponível em: <http://www.agricultura.gov.br/assuntos/sustentabilidade/ indicacao-geografica/o-que-e-indicacao-geografica-ig $>$. Acesso em: 26 jan. 2018.

CALDAS, A.S.; CERQUEIRA, P.S.; PERIN, T.F. Mais além dos arranjos produtivos locais: as indicações geográficas protegidas como unidades de desenvolvimento local. RDE-Revista de Desenvolvimento Econômico, v. 7, n. 11, 2005.

DELGADO, M.; PORTER, M.E.; STERN, S. Clusters, convergence, and economic performance. National Bureau of Economic Research, 2012.

DE LIMA FANTE, C.C.; DALLABRIDA, V.R. Governança territorial em experiências de Indicação Geográfica: análises e prospecções. Desenvolvimento Regional em debate: DRd, v. 6, n. 2, p. 228-246, 2016.

DOS ANJOS, F.S.; CRIADO, E.A.; CALDAS, N.V. Indicações geográficas e desenvolvimento territorial: um diálogo entre a realidade europeia e brasileira. Dados - Revista de Ciências Sociais, v. 56, n. 1, 2013.

GASCÓN, J.M.H. et al. Clusters and competitiveness: the case of Catalonia (1993-2010). Generalitat de Catalunya, Government of Catalonia, Ministry of Enterprise and Labour, 2010.

GIOVANNUCCI, D.; BARHAM, E.; PIROG, R. Defining and marketing "local" foods: geographical indications for US products. The Journal of World Intellectual Property, v. 13, n. 2, p. 94-120, 2010.

GODOY, A. S. Estudo de caso qualitativo. In: Pesquisa qualitativa em estudos organizacionais: paradigmas, estratégias e métodos. São Paulo: Saraiva, 2006, p. 115-146.

GUIMARÃES FILHO, C. Certificação de indicação geográfica. Uma estratégia de inserção no mercado para produtos do Semiárido. Secretaria da Agricultura,
Pecuária, Irrigação, Reforma Agrária, Pesca e Aquicultura do Estado da Bahia. 2013. Disponível em: < http://www. agricultura.gov.br/desenvolvimento-sustentavel/ indicacao-geografica >. Acesso em: 16 jan. 2018.

GUIMARÃES, E.R. et al. The brand new Brazilian specialty coffee market. Journal of Food Products Marketing, v. 25, n. 1, p. 49-71, 2018.

INPI - Instituto Nacional de Propriedade Industrial. Revista de propriedade Industrial, Seção I, n. 2243, 2013. Disponível em: <http://revistas.inpi.gov.br/rpi/>. Acesso em: 16 jan. 2018.

LEME, P.H.M.V.; SILVA, E.C.; SETTE, R.S. Qualidade com sustentabilidade: certificações do agronegócio café sob a ótica dos pilares da qualidade. In: 50으 Congresso da sociedade brasileira de economia, administração e sociologia rural - SOBER. Anais... Vitória: Sober, 2012.

MACKE, J. A pesquisa-ação como estratégia de pesquisa participativa. In: Pesquisa qualitativa em estudos organizacionais: paradigmas, estratégias e métodos. São Paulo: Saraiva, 2006, p. 208-239.

MAFRA, L.A.S. Indicação geográfica e construção do mercado: a valorização da origem no Cerrado Mineiro, 2008. Tese (Doutorado em Ciências Sociais). Rio de Janeiro: UFRRJ, 2008.

MARTELETO, R.M.; SILVA, A.B.O. Redes e capital social: o enfoque da informação para o desenvolvimento local. Ciência da Informação, Brasília, v. 33, n. 3, p. 41-49, 2004.

NIEDERLE, P.A. Controvérsias sobre a noção de Indicações Geográficas enquanto instrumento de desenvolvimento territorial: a experiência do Vale dos Vinhedos em questão. In: 47o Congresso da sociedade brasileira de economia, administração e sociologia rural - SOBER. Anais... Porto Alegre: Sober, 2009.

ORTEGA, A.C. Territórios deprimidos: desafios para as políticas de desenvolvimento rural. Campinas: Alínea, 2008.

; _. Território, certificação de procedência e a busca da singularidade: o caso do Café do Cerrado. Política e Sociedade, v. 10, n. 19, p. 305-330, 2011.

; JESUS, M.C. Café e território. A cafeicultura no Cerrado Mineiro. Campinas: Alínea, 2012.

PIERANTI, O. P. A metodologia historiográfica na pesquisa em administração: uma discussão acerca dos princípios e de sua aplicabilidade no Brasil Contemporâneo. Cadernos Ebape, v. 6, n. 1, 2008. 
PORTER, M.E. Clusters and the new economics of competition. Boston: Harvard Business Review, 1998.

SAES, M.S.M.; JAYO, M.; DA SILVEIRA, R.L.F. Caccer: coordenando ações para a valorização do Café do Cerrado. In: VII Seminário Internacional PENSA de Agribusiness. Anais... São Paulo, 1997.

SAES, M.S.M. et al. Competitividade do sistema agroindustrial do café. In: FARINA, E.M.M.Q.; ZYLBERSLTAJN, D. (Eds.). Competitividade no agribusiness brasileiro. 4. ed. São Paulo: USP, 1998, p. 3-136.

THAINES, A.H. Desenvolvimento regional sob a ótica do reconhecimento da indicação geográfica: o case do Vale dos Vinhedos. 2012.

VALE, G.M.V.; AMÂNCIO, R.; DE LIMA, J.B. Criação e gestão de redes: uma estratégia competitiva para empresas e regiões. Revista de Administração da Universidade de São Paulo, v. 41, n. 2, 2006.

VALE, G.M.V.; AMÂNCIO, R.; LAURIA, M.C.P. Capital social e suas implicações para o estudo das organizações. OES - Organizações e Sociedade, v. 13, n. 36, p. 45-63, 2006.

VALENTE, M.E.R. et al. Indicação geográfica de alimentos e bebidas no Brasil e na União Europeia. Ciência Rural, v. 42, n. 3, 2012.

VALENTE, M.E.R. et al. O processo de reconhecimento das indicações geográficas de alimentos e bebidas brasileiras: regulamento de uso, delimitação da área e diferenciação do produto. Ciência Rural, v. 43, n. 7, p. 1330-1336, 2013.

VIEIRA, A.C.P.; PELLIN, V. O uso do instituto das indicações geográficas como instrument de promoção do desenvolvimento territorial rural - 0 caso dos Vales da Uva Goethe Brasil SC. In: 20 APDR Congress Renaissance of the regions of southern europe, 2014, Evora: APDR Congress, 2014. v. 1. p. 822-831.

WHITTINGTON, R. The practice turn in organization research: Towards a disciplined transdisciplinarity. Accounting, Organizations and Society, v. 36, n. 3, p. 183186, 2011.

Todo o conteúdo deste periódico, exceto onde estiver identificado, está licenciado sob uma Licença Creative Commons (cc by 4.0). 
